Washington University School of Medicine Digital Commons@Becker

2015

\title{
Biomechanical determination of distal level for fusions across the cervicothoracic junction
}

\author{
Ivan Cheng \\ Stanford University \\ Eric B. Sundberg \\ Stanford University \\ Alex lezza \\ Stanford University \\ Derek P. Lindsey \\ The Veterans Administration Health Care System \\ K. Daniel Riew \\ Washington University School of Medicine in St. Louis
}

Follow this and additional works at: https://digitalcommons.wustl.edu/open_access_pubs

Please let us know how this document benefits you.

\section{Recommended Citation}

Cheng, Ivan; Sundberg, Eric B.; lezza, Alex; Lindsey, Derek P.; and Riew, K. Daniel, "Biomechanical determination of distal level for fusions across the cervicothoracic junction." Global Spine Journal. 5, 4. 282-286. (2015).

https://digitalcommons.wustl.edu/open_access_pubs/4527

This Open Access Publication is brought to you for free and open access by Digital Commons@Becker. It has been accepted for inclusion in Open Access Publications by an authorized administrator of Digital Commons@Becker. For more information, please contact vanam@wustl.edu. 


\title{
Biomechanical Determination of Distal Level for Fusions across the Cervicothoracic Junction
}

\author{
${ }^{1}$ Department of Orthopaedic Surgery, Stanford University Medical \\ Center, Stanford, California, United States \\ 2 Redwood Orthopaedic Surgery Associates, Santa Rosa, \\ California, United States \\ ${ }^{3}$ Bone and Joint Rehabilitation R\&D Center, The Veterans \\ Administration Health Care System, Palo Alto, \\ California, United States \\ ${ }^{4}$ Department of Orthopaedic Surgery, Washington University in \\ St. Louis, Saint Louis, Missouri, United States \\ Global Spine ] 2015;5:282-286.
}

Ivan Cheng ${ }^{1} \quad$ Eric B. Sundberg ${ }^{1} \quad$ Alex lezza $^{1,2} \quad$ Derek P. Lindsey ${ }^{3} \quad$ K. Daniel Riew ${ }^{4}$

\begin{abstract}
Keywords

- adjacent segment pathology

- intradiscal pressure

- cervicothoracic junction

- in vitro testing

Study Design In vitro testing.

Objective To determine whether long cervical and cervicothoracic fusions increase the intradiscal pressure at the adjacent caudal disk and to determine which thoracic end vertebra causes the least increase in the adjacent-level intradiscal pressure.

Methods A bending moment was applied to six cadaveric cervicothoracic spine specimens with intact rib cages. Intradiscal pressures were recorded from C7-T1 to T9-10 before and after simulated fusion by anterior cervical plating and posterior thoracic pedicle screw constructs. The changes in the intradiscal pressure from baseline were calculated and compared.

Results No significant differences where found when the changes of the juxtafusion intradiscal pressure at each level were compared for the flexion, extension, and left and right bending simulations. However, combining the pressures for all directions of bending at each level demonstrated a decrease in the pressures at the T2-T3 level. Exploratory analysis comparing changes in the pressure at T2-T3 to other levels showed a significant decrease in the pressures at this level $(p=0.005)$.

Conclusions Based on the combined intradiscal pressures alone it may be advantageous to end long constructs spanning the cervicothoracic junction at the $\mathrm{T} 2$ level if there are no other mitigating factors.
\end{abstract}

\author{
Address for correspondence Ivan Cheng, MD, 450 Broadway Street, \\ MC 6342, Redwood City, CA 94063, United States \\ (e-mail: ivan.cheng@stanford.edu).
}

\section{Introduction}

Adjacent segment pathology is known to occur in $\sim 25 \%$ of patients who have undergone anterior cervical diskectomy and fusion within 10 years of the operation. ${ }^{1}$ This postoperational degeneration occurs at a steady rate of $\sim 2.9 \%$ of patients per year. The cause of this early adjacent disk degeneration has not been fully elucidated. Currently, two differing ideas exist as to what causes this degeneration.
Some groups hypothesize that eliminating motion of spinal segments leads to increased forces on the adjacent segments. ${ }^{2-4}$ Other groups suggest that the disk degeneration is simply part of a natural process. ${ }^{5-7}$

Eliminating motion by performing a fusion has been shown to increase the intradiscal pressure at the adjacent levels in biomechanical models. Eck et al simulated a fusion at C5-C6 and reported increases in the intradiscal pressures at both adjacent received

September 7, 2014 accepted after revision December 31, 2014 published online February 11, 2015
Dol http://dx.doi.org/ 10.1055/s-0035-1546418. ISSN 2192-5682. (c) 2015 Georg Thieme Verlag KG
Stuttgart · New York

License terms

(요 (1) $\Theta \circledast$ 
levels during flexion when compared with the prefusion values. ${ }^{8}$ Using a model reproducing a two-level C5-C7 fusion, Park et al showed increases in the intradiscal pressure at C4-C5 after fusion. ${ }^{9}$ Increases in the cervical intradiscal pressure after adjacent-level fusion, however, are not universally reproducible.

Patients who had long cervical fusions down to C7 may experience degeneration at the level adjacent to the most caudally fused segment. The purpose of our study is to determine whether long cervical and cervicothoracic fusions increase the intradiscal pressure at the adjacent caudal disk. Furthermore, we hoped to determine which thoracic end vertebra causes the least amount of increase in the adjacentlevel intradiscal pressure. This may provide information about which level is the most ideal to end a fusion crossing the cervicothoracic junction. We hypothesized that extending past $\mathrm{T} 1$ and ending the fusion in the upper thoracic spine would provide a more biomechanically sound construct because of the added stability from the rib cage. Our hope is that this knowledge will enable surgeons to perform selective posterior fusions to levels that are better able to accommodate the stiff lever arm of a cervical fusion.

\section{Methods}

Six fresh frozen cadaveric cervicothoracic spine specimens with intact rib cages and sternums were dissected. The extraneous soft tissue was removed and care was taken to preserve the costovertebral joints, costosternal joints, facet joints, capsular ligaments, interspinous ligaments, supraspinous ligament, ligamentum flavum, anterior longitudinal ligament, and posterior longitudinal ligament in each specimen. The atlas and occiput were removed, and the specimens were stabilized caudally by potting T12 in polymethyl methacrylate and securing the cement block to a table using vice grips. The lumbar spine and pelvis were not included in these specimens to focus on pressure changes only within the thoracic spine. A vertically oriented screw was placed in the odontoid process to allow for attachment of a mechanical force gauge.

A 14-gauge angiocatheter was placed through the anterior annulus into the center of the nucleus pulposus at the C7-T1 level. Gross visualization and direct measurements of the depth of disk were used to determine the location of the center of the disk. The location of the pressure transducer was further confirmed using fluoroscopy. A pressure transducer calibrated to 17 bar (Samba Preclin 360 HP, BIOPAC Systems, Goleta, California, United States) was introduced into the disk through the catheter. The catheter was then removed and with the spine in the neutral position the reference value for disk pressure was recorded digitally on a Samba 201 pressure measurement system (BIOPAC Systems). Flexion, extension, left, and right bending forces of $25 \mathrm{~N}$ were applied manually through the screw placed in the dens using the mechanical force gauge. A force of $25 \mathrm{~N}$ was chosen after pilot experiments as appropriate magnitude, allowing the specimen to return to its original, upright position, without irreversible damage. ${ }^{10}$ The disk pressure was recorded after the application of each bending moment. The same process was performed on each disk from C7-T1 to T9-T10 to obtain baseline pressures.
The cervical spine was then plated anteriorly from C3 to C7 using an anterior cervical plate (Stryker Spine, Kalamazoo, Michigan, United States). We simulated a common clinical scenario with previous multilevel anterior fusions ending at $\mathrm{C} 7$ resulting in degeneration at the cervicothoracic junction. The C7-T1 disk pressure was recorded again in the neutral position and after application of bending forces in four positions: flexion, extension, and left and right bending. Lateral mass screws were then placed in C5 and C6 and attached to pedicle screws in T1. Four points of fixation posteriorly above the cervicothoracic junction were deemed sufficient fixation after a previous anterior fusion. All the pedicle screws were placed in a straight-ahead trajectory using a freehand technique. ${ }^{11}$ The T1-T2 disk pressures were recorded again in all five positions. Sequential extension of the posterior construct was performed using polyaxial pedicle screws one level at a time (Stryker Spine; - Fig. 1). The intradiscal pressures were measured at the subjacent disk from C7-T1 to T9-T10.

The changes in the intradiscal pressure for each level were calculated using the formula: (post bending value - post neutral value) - (pre bending value - pre neutral value), where post is postinstrumentation and pre is preinstrumentation.

The changes at each level were averaged and analyzed statistically using a one-way analysis of variance, with $p$ values $<0.05$ considered significant. The pressure changes at each level for flexion, extension, and lateral bending were combined and a post hoc analysis was performed.

\section{Results}

The changes in the intradiscal pressure for each level are shown in graph format in - Figs. $\mathbf{2}$ and $\mathbf{3}$ for flexion-extension and lateral bending, respectively. There were no significant differences ( $p 0.13$ to 0.89 ) when comparing the changes of the juxtafusion intradiscal pressure at each level for the separate forces of flexion, extension, and left and right bending. In flexion, the largest mean increase in the intradiscal pressure occurred at the T6-T7 level, and in extension the largest increase occurred at T8-T9. In left and right bending together, the largest increase occurred at T9-T10.

Post hoc analysis revealed decreases in the intradiscal pressure when combining all forces at T2-T3 and T7-T8. In an exploratory analysis, a $t$ test comparing the combined changes in the intradiscal pressure for flexion, extension, and lateral bending at T7-T8 to other levels did not show a significant difference $(-30.8 \mathrm{kPa}$ versus $-16.1 \mathrm{kPa} p=0.76)$. A $t$ test comparing combined the intradiscal pressure changes at T2-T3 to other levels did show a significant difference $(-141.0 \mathrm{kPa}$ versus $-3.3 \mathrm{kPa}, p=0.005)$.

\section{Discussion}

Adjacent segment pathology is a general term applicable to both the radiographic and clinical (CASP) changes at a segment adjacent to a previously operated spinal motion segment. ${ }^{12}$ Recently, Lawrence et al performed a systematic review to determine the risk of adjacent segment pathology in the 


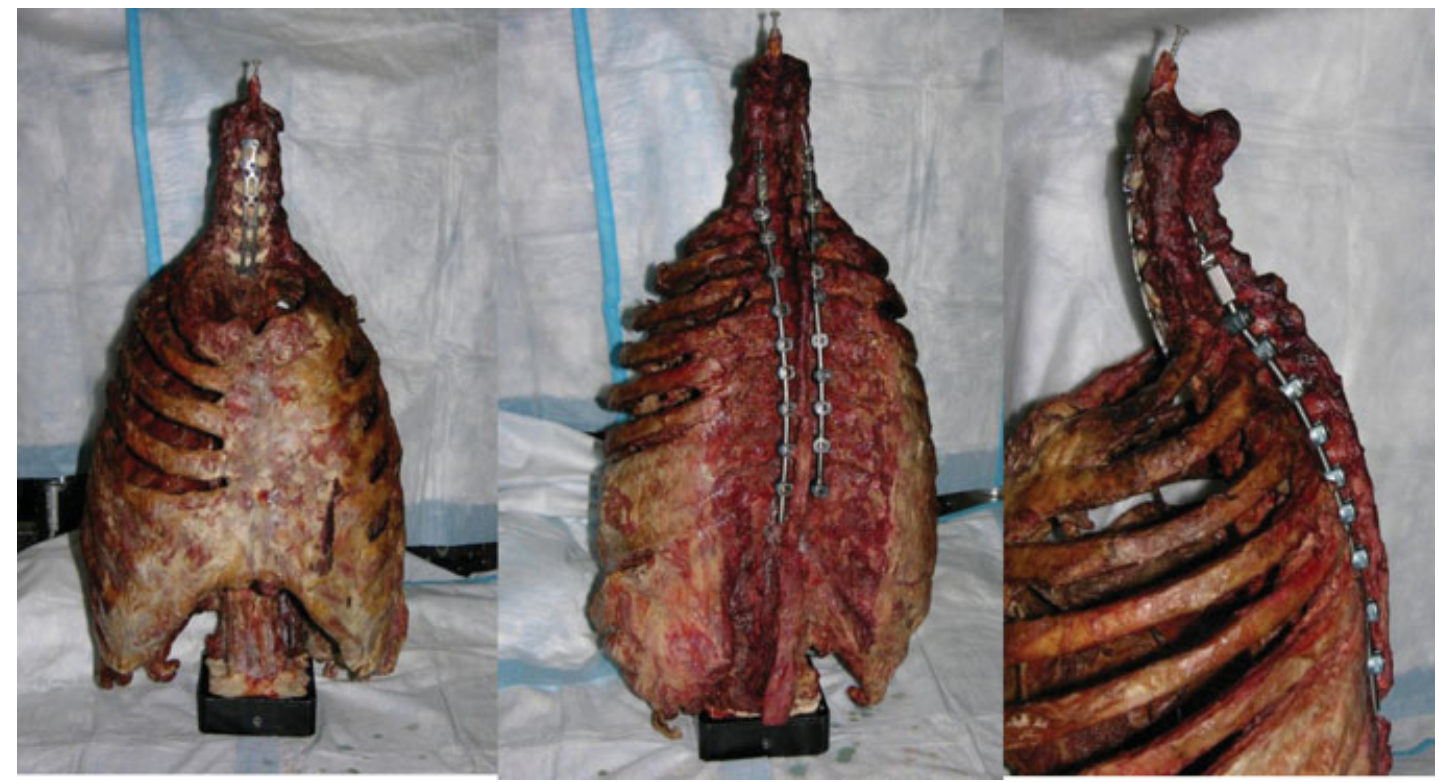

Fig. 1 Anterior, posterior, and lateral views of an instrumented specimen.

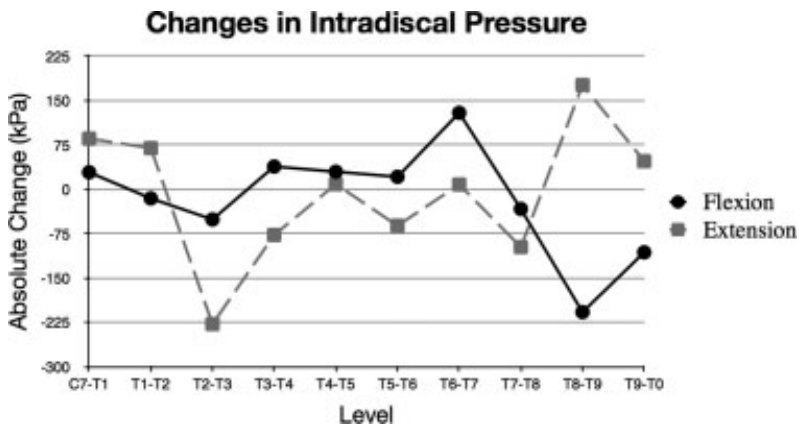

Fig. 2 Graph showing the absolute change between preinstrumented and postinstrumented adjacent-level intradiscal pressure at each level between C7-T1 and T9-T10 for flexion and extension.

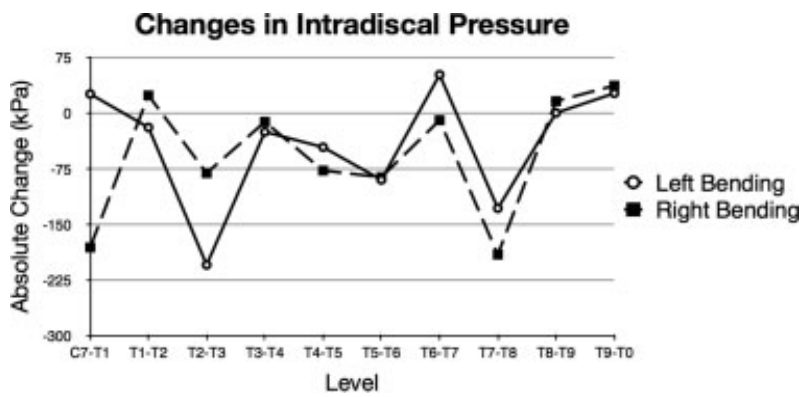

Fig. 3 Graph showing the absolute change between preinstrumented and postinstrumented adjacent-level intradiscal pressure at each level between C7-T1 and T9-T10 for lateral bending.

cervical spine. ${ }^{13}$ They found the prevalence of CASP to range from 11 to $12 \%$ at 5 years, 16 to $38 \%$ at 10 years, and $33 \%$ at 17 years. They also found factors that may contribute to the development of CASP including age less than 60 years, fusing adjacent to $\mathrm{C} 5-\mathrm{C} 6$ and/or $\mathrm{C} 6-\mathrm{C} 7$ levels, a pre-existing disk herniation, and/or dural compression secondary to spinal stenosis. Multiple biomechanical studies have focused on the effects of multilevel fusions on the adjacent levels. Prasarn et al demonstrated an increase in the sagittal range of motion of $31.3 \%$ above and $33.9 \%$ below a fused motion segment after comparing a two-level with a one-level anterior cervical diskectomy and fusion. ${ }^{14}$ Another biomechanical study by Dmitriev et al also showed an increased range of motion at the distal level following C3-C6 arthrodesis. ${ }^{15}$

Quantifying mechanical demands on intervertebral disks is important because these increased demands are known to have adverse effects on the disk. The stress on the disk can interfere with its nutritional requirements and cause early degeneration. ${ }^{16}$ The intervertebral disk relies on the diffusion of nutrients from the peripheral blood vessels and vertebral end plates through the extracellular matrix because it lacks a true blood supply. Therefore, an increase in pressure may interfere with the entrance of nutrients to the intervertebral disk as well as the escape of waste products. The accumulation of waste products leads to increased levels of lactate, which results in increased $\mathrm{pH}$ and impaired metabolism. ${ }^{17}$ Normal aging processes such as an increase in collagen type 1 and a decrease in collagen type 2, proteoglycans, and chondroitin sulfate are also accelerated with increased pressure on the intervertebral disk, and these changes lead to disk degeneration. ${ }^{18}$

Theoretically, fusing caudally into the thoracic spine may result in less change in the adjacent-level intradiscal pressure due to the inherent stability of the ribs. A fusion into the thoracic spine would also avoid ending a construct at the cervicothoracic junction, an area of potential instability where the lordotic and mobile cervical spine meets the rigid and kyphotic lumbar spine. ${ }^{19}$ Longer constructs, however, increase the lever arm and may overcome the stability of the ribcage, increasing the adjacent-level pressure. The compromise between these two concepts may have a balancing effect on the intradiscal pressure changes. Our hypothesis was that these opposing biomechanical 
concepts would create an equilibrium that would allow for lower-pressure changes in the upper thoracic spine.

Our outcomes contrast with some previously published results. In the cervical spine, Eck et al showed an increase in mobility and intradiscal pressure in spinal segments adjacent to fusions during the simulation of physiologic movements. ${ }^{8}$ Specifically, the segmental motion and intradiscal pressure during flexion and extension were measured at $\mathrm{C4}-\mathrm{C5}$ and $\mathrm{C6}-\mathrm{C} 7$ before and after the fusion of $\mathrm{C} 5-\mathrm{C} 6$ by anterior plating. The results show significant increases in pressure during flexion at both the C4-C5 level (73.2\%) and the C6-C7 level (45.3\%). In our model, we did not observe significant changes in the pressure after adjacent-level fusion. Our study differed from the Eck model in several important ways. Notably, our bending was force-controlled and the Eck team used a displacement-controlled model. The authors did not report the prefusion and postfusion bending moments. We also started our pressure measurements at the cervicothoracic junction and proceeded caudally, and the analyzed intradiscal pressures in the Eck study were centered at the midcervical spine.

In concordance with our study, increases in the cervical juxtafusion intradiscal pressures have not been universally reproducible in biomechanical models. Rao et al simulated C5-C6 grafted fusion and C5-C6 anterior plating. ${ }^{20}$ Like in our study, they observed high interspecimen variability in the intradiscal pressure measurements. They reported a significant reduction in the intradiscal pressure of the superior adjacent disk after both grafted fusion and anterior plating. In extension, there were no significant changes in the intradiscal pressure at the inferior adjacent disk. In our model, we did not see significant increases in the intradiscal pressure at C7-T1 with any bending motion after simulating a fusion from C3-C7. That being said, the largest increases in intradiscal pressure occurred with the constructs ending from T6 to T9. Surgeons may consider ending constructs that cross the cervicothoracic junction in the upper thoracic spine rather than the mid to lower thoracic regions. In fact, the lowest combined pressures were measured at T2-T3. This may be due to a balance between the increasing stress of a longer lever arm with the increased stability of the thoracic ribs. In situations where there is lack of focal kyphosis or significant instability, it may be feasible to end constructs at T2.

This study had several weaknesses. There are inherent limitations that come with cadaveric biomechanical studies. Our model could not account for the changes that the surgical dissection and instrumentation have on living tissue nor could it incorporate the effects of active muscular control. In addition, we did not measure the changes in the motion or facet pressures at the levels adjacent to our fusion. The adjacent-level motion changes and facet loading may contribute to early disk degeneration. $^{21,22}$ Treating physicians must also take into account individual patient anatomy that may influence the choice of caudal fusion levels, such as a kyphotic deformity, listhetic instability, or pre-existing disk/facet arthropathy. In fact, we found that some of the specimens had significant degeneration at multiple levels of the thoracic spine leading to asymmetric collapse, osteophyte formation, and facet hypertrophy on one side more than the other without significant deformity. This may explain some of the variation in values between left and right bending at specific levels. Also, simulating a multilevel anterior fusion ending at $\mathrm{C7}$ may not be biomechanically equivalent to a posterior fusion construct ending at C7, and future biomechanical studies should be performed for this clinical scenario. Finally, we did not load our specimens to failure, therefore we could not comment on other causes of failure of long cervicothoracic fusions such as caudal-level instrumentation pullout or breakage.

\section{Conclusion}

We did not find a significant difference in intradiscal pressure changes when analyzing flexion, extension, and lateral bending separately. However, in an exploratory analysis, the combined change in the juxtafusion intradiscal pressure for flexion, extension, and lateral bending at T2-T3 was significantly less than the combined pressure at other levels. Although this change needs to be confirmed with future studies also analyzing facet pressures and three-dimensional motion, it may reflect a balance between the rigidity afforded by the rib cage in the thoracic spine and the length of the lever arm of the construct. When crossing the cervicothoracic junction with long cervical fusions, surgeons may want to consider stopping at the T2-T3 level if there are no other mitigating factors.

\section{Funding}

The study was supported by Stryker Spine (Kalamazoo, Michigan).

\section{Disclosures}

Ivan Cheng, Grants: Stryker Spine; Consultant: Nuvasive, Stryker Spine; Royalties: Nuvasive; Stock/stock options: Cytonics

Eric B. Sundberg, reimbursed for travel expenses for presenting this work

Alex Iezza, none

Derek P. Lindsey, Employment: SI-Bone; Stock/stock options: SI-Bone

K. Daniel Riew, Board membership: CSRS, KASS, AOSpine; Royalties: Biomet, Medtronic, Osprey; Stock/stock options: Amedica, Benvenue, Expanding Orthopedics, Nexgen

Spine, Osprey, Paradigm Spine, Spinal Kinetics, Spineology, Vertiflex, PSD

Note

Of note, lateral mass screws were used in this study and are not U.S. Food and Drug Administration-approved for this indication.

\section{Acknowledgment}

We would like to acknowledge Alex Sox-Harris, PhD, for his assistance in the statistical analysis of the data in this study. 


\section{References}

1 Hilibrand AS, Carlson GD, Palumbo MA, Jones PK, Bohlman HH. Radiculopathy and myelopathy at segments adjacent to the site of a previous anterior cervical arthrodesis. J Bone Joint Surg Am 1999;81(4):519-528

2 Brodke DS, Zdeblick TA. Modified Smith-Robinson procedure for anterior cervical discectomy and fusion. Spine (Phila Pa 1976) 1992;17(10, Suppl):S427-S430

3 Blumenthal SL, Ohnmeiss DD, Guyer RD, Zigler JE. Reoperations in cervical total disc replacement compared with anterior cervical fusion: results compiled from multiple prospective food and drug administration investigational device exemption trials conducted at a single site. Spine (Phila Pa 1976) 2013;38(14):1177-1182

4 Mummaneni PV, Amin BY, Wu JC, Brodt ED, Dettori JR, Sasso RC. Cervical artificial disc replacement versus fusion in the cervical spine: a systematic review comparing long-term follow-up results from two FDA trials. Evid Based Spine Care J 2012;3 (S1):59-66

5 Park JY, Kim KH, Kuh SU, Chin DK, Kim KS, Cho YE. What are the associative factors of adjacent segment degeneration after anterior cervical spine surgery? Comparative study between anterior cervical fusion and arthroplasty with 5-year follow-up MRI and CT. Eur Spine J 2013;22(5):1078-1089

6 Cho SK, Riew KD. Adjacent segment disease following cervical spine surgery. J Am Acad Orthop Surg 2013;21(1):3-11

7 Harrod CC, Hilibrand AS, Fischer DJ, Skelly AC. Adjacent segment pathology following cervical motion-sparing procedures or devices compared with fusion surgery: a systematic review. Spine (Phila Pa 1976) 2012;37(22, Suppl):S96-S112

8 Eck JC, Humphreys SC, Lim TH, et al. Biomechanical study on the effect of cervical spine fusion on adjacent-level intradiscal pressure and segmental motion. Spine (Phila Pa 1976) 2002;27(22): 2431-2434

9 Park DH, Ramakrishnan P, Cho TH, et al. Effect of lower two-level anterior cervical fusion on the superior adjacent level. J Neurosurg Spine 2007;7(3):336-340

10 Horton WC, Kraiwattanapong C, Akamaru T, et al. The role of the sternum, costosternal articulations, intervertebral disc, and facets in thoracic sagittal plane biomechanics: a comparison of three different sequences of surgical release. Spine (Phila Pa 1976) 2005; 30(18):2014-2023
11 Kim YJ, Lenke LG, Bridwell KH, Cho YS, Riew KD. Free hand pedicle screw placement in the thoracic spine: is it safe? Spine (Phila Pa 1976) 2004;29(3):333-342, discussion 342

12 Riew KD, Norvell DC, Chapman JR, Skelly AC, Dettori JR. Introduction/summary statement: adjacent segment pathology. Spine (Phila Pa 1976) 2012;37(22, Suppl):S1-S7

13 Lawrence BD, Hilibrand AS, Brodt ED, Dettori JR, Brodke DS. Predicting the risk of adjacent segment pathology in the cervical spine: a systematic review. Spine (Phila Pa 1976) 2012;37(22, Suppl):S52-S64

14 Prasarn ML, Baria D, Milne E, Latta L, Sukovich W. Adjacent-level biomechanics after single versus multilevel cervical spine fusion. J Neurosurg Spine 2012;16(2):172-177

15 Dmitriev AE, Kuklo TR, Lehman RA Jr, Rosner MK. Stabilizing potential of anterior, posterior, and circumferential fixation for multilevel cervical arthrodesis: an in vitro human cadaveric study of the operative and adjacent segment kinematics. Spine (Phila Pa 1976) 2007;32(6):E188-E196

16 Grunhagen T, Shirazi-Adl A, Fairbank JC, Urban JP. Intervertebral disk nutrition: a review of factors influencing concentrations of nutrients and metabolites. Orthop Clin North Am 2011;42(4):465-477, vii

17 Buckwalter JA. Aging and degeneration of the human intervertebral disc. Spine (Phila Pa 1976) 1995;20(11):1307-1314

18 Hutton WC, Toribatake Y, Elmer WA, Ganey TM, Tomita K, Whitesides TE. The effect of compressive force applied to the intervertebral disc in vivo. A study of proteoglycans and collagen. Spine (Phila Pa 1976) 1998;23(23):2524-2537

19 An HS, Vaccaro A, Cotler JM, Lin S. Spinal disorders at the cervicothoracic junction. Spine (Phila Pa 1976) 1994;19(22):2557-2564

20 Rao RD, Wang M, McGrady LM, Perlewitz TJ, David KS. Does anterior plating of the cervical spine predispose to adjacent segment changes? Spine (Phila Pa 1976) 2005;30(24): 2788-2792, discussion 2793

21 Little JS, Ianuzzi A, Chiu JB, Baitner A, Khalsa PS. Human lumbar facet joint capsule strains: II. Alteration of strains subsequent to anterior interbody fixation. Spine J 2004;4(2):153-162

22 Sim HB, Murovic JA, Cho BY, Lim TJ, Park J. Biomechanical comparison of single-level posterior versus transforaminal lumbar interbody fusions with bilateral pedicle screw fixation: segmental stability and the effects on adjacent motion segments. J Neurosurg Spine 2010;12(6):700-708 